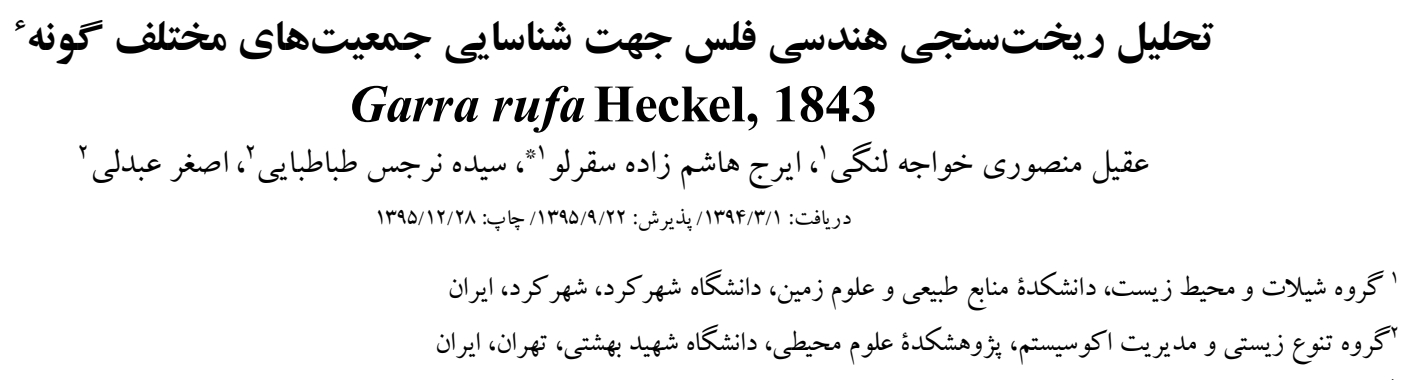

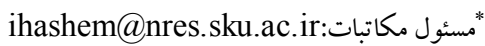

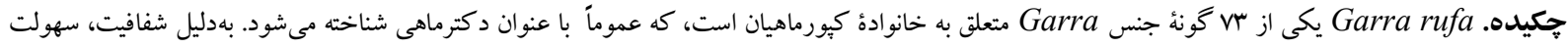

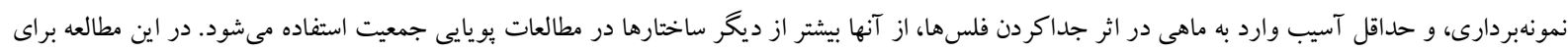

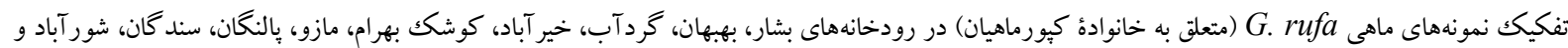

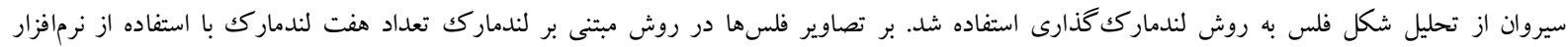

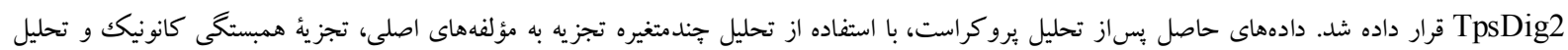

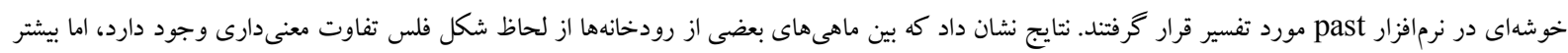

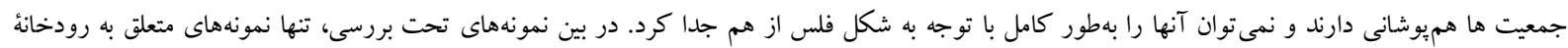

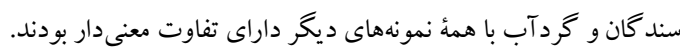

$$
\begin{aligned}
& \text { وازههاى كليدى. TpsDig2، Garra rufa، تحليل يروكراست، مؤلفهاى اصلى، لندماركى }
\end{aligned}
$$

\title{
Geometric analysis of the scale shape to discriminate different populations of Garra rufa Heckel, 1843
}

Aghil Mansouri Khajeh Langi ${ }^{1}$, Iraj Hashemzadeh Segherloo ${ }^{1 *}$, Seyedeh Narjes Tabatabaei ${ }^{2}$ \& Asghar Abdoli ${ }^{2}$

Received 22.05.2016/ Accepted 12.12.2016/ Published 18.03.2017

${ }^{1}$ Department of Fisheries and Environmental Sciences, Faculty of Natural Resources and Earth Sciences, Shahr-e-Kord University, Shahr-e-Kord, Iran

${ }^{2}$ Department of Biodiversity and Ecosystem Management, Environmental Sciences Research Center, Shahid Beheshti University, Tehran, Iran

*Correspondent author: ihashem@nres.sku.ac.ir

\begin{abstract}
Garra rufa is one of the 73 Garra species of the family Cyprinidae. Scales are used more commonly than any other structure in population dynamic studies, because of their transparency, ease of sampling, and the minimal injuries caused to the fish during their removal. To discriminate fish from different rivers including Bashar, Behbahan, Gerdab, Kheirabad, Kooshk-e-Bahram, Mazoo, Palangan, Sendegan, Shoor-Abad, and Sirvan Rivers using geometric morphometric analyses of the scale shape, landmark based geometric morphometrics method was used. Seven landmark points were depicted on each scale using the software TpsDig2. After procrustes analyses, landmark data were exposed to principle component analysis (PCA), CVA, and cluster analyses using the past software. The results showed that there were significant scale shape differences among some populations, but most of the samples showed overlapping shape distribution and could not be separated robustly. Among the samples which were analyzed, only the Sendegan and Gerdab river samples did not show significant difference in scale shape compared to all other samples.
\end{abstract}

Keywords. TpsDig2, procruses analysis, principle components, landmark

فلس، دو جفت سبيلك، يك ديسك دهانى جسبندة توسعه يافته با

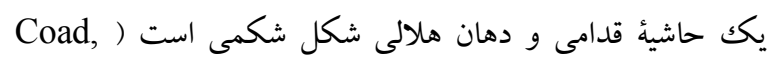

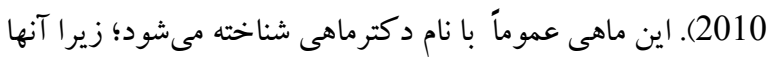

مقدمه

ماهى Gufa rufa يكى از rv كو نهُ جنس Garra است ( Esmaeili (et al., 2009; Coad, 2010 
روشها جدا مى كند اين است كه در اين روش از جايگاههاى

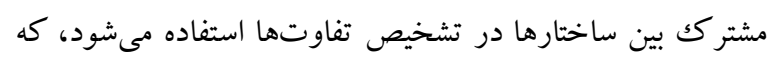

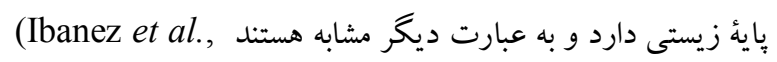

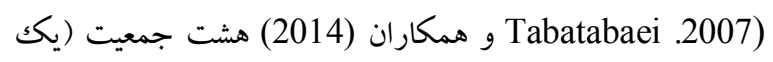

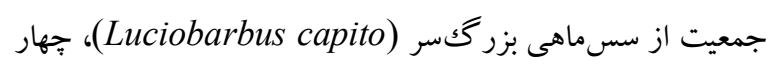
جمعيت از ماهى خياطه (Alburnoides eichwaldii) و دو دو اهو جمعيت از ماهى سفيد (Rutilus frisii kutum))، متعلق به اهي

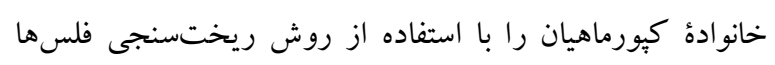

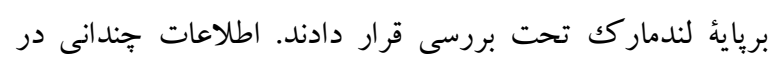

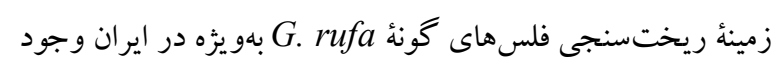

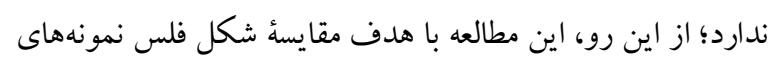

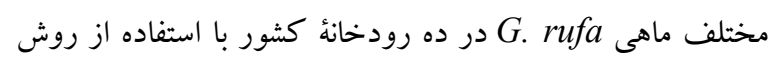

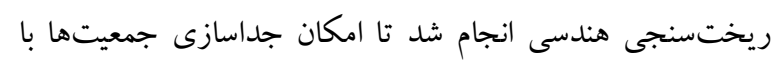

$$
\text { استفاده از شكل فلس بررسى شود. }
$$

\section{مواد و روشها}

براى جمع آورى نمونههاى ماهى Gufa از ساجو كو كـ با قطر

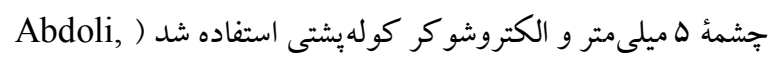

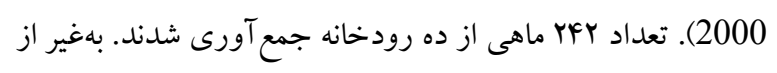

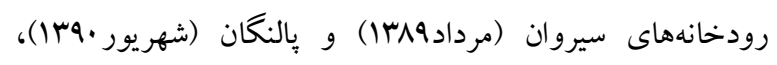
نمونههاى متعلق به ايستخاههاى ديخر در مدت يكسال (ارديبهشت

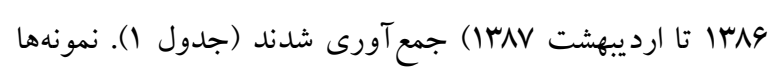

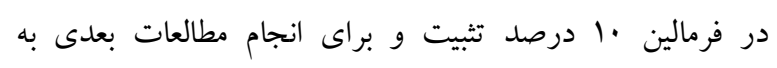

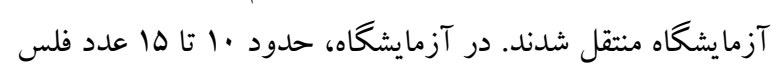

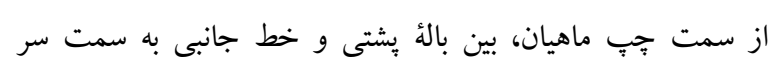

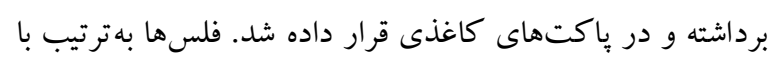

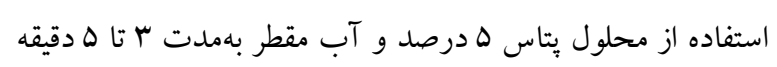

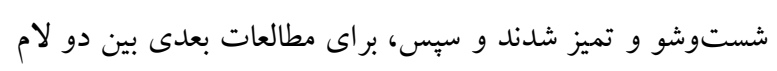

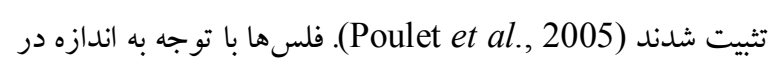

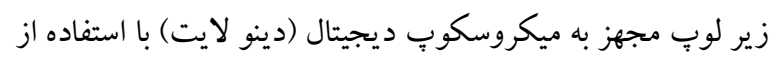

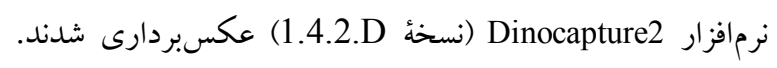

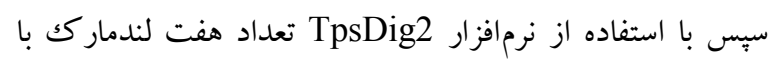
توجه به ويز گى مشترك به منزله نقاط ثابت و مشابه فلس روى

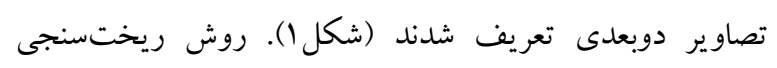

مىتوانند از يوست مرده تغذيه كنند و بههمين علت در استخرهاى شنا رها مىشوند و در درمان موقت پِوريازيس مورد استفاده قرار

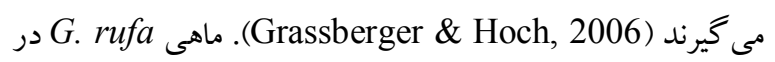

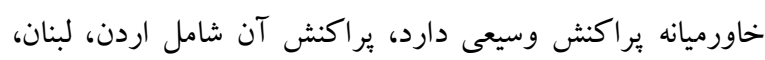

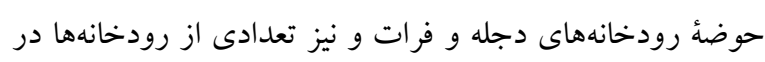

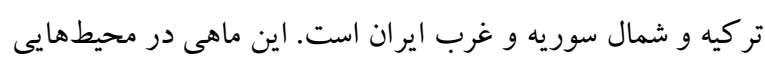

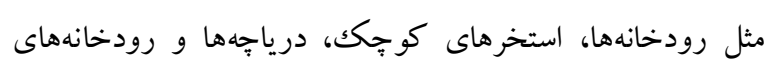

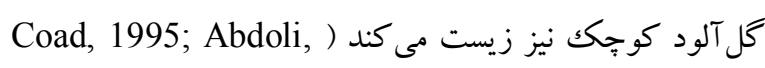
2000). شفافيت نسبى فلس ها، سهولت نمونهبردارى و و حداقل

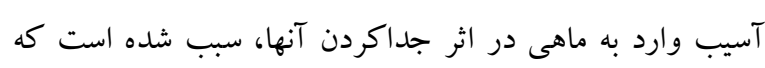

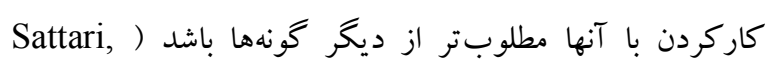

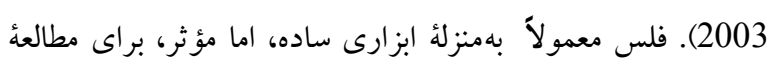

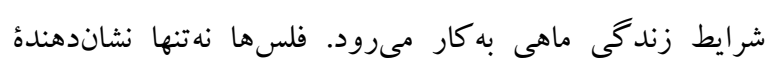

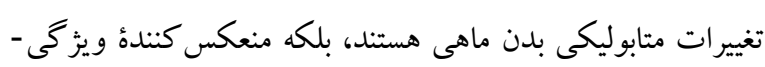

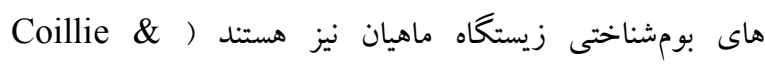
Rousseau, 1974; Johal \& Sawhney, 1997; Esmaeili ز از (et al., 2009; Johal \& Dua, 1994

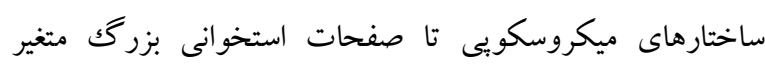

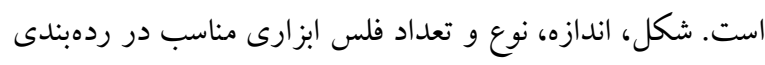

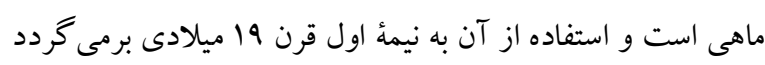

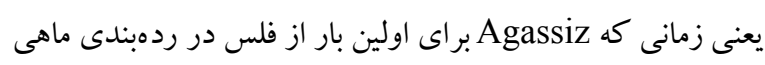

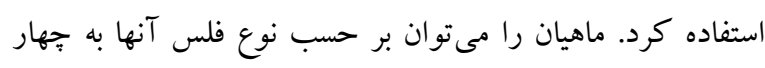

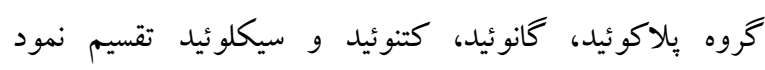
(Jawad \& AL-Jufaili, 2007)

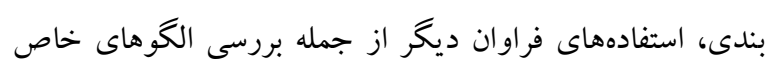
رشد، تاريخجه زندكى ماهىها و شناسايى جمعيتها و ذخاير آنها

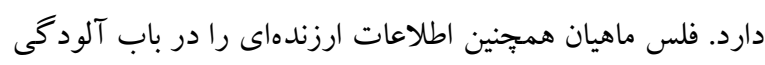

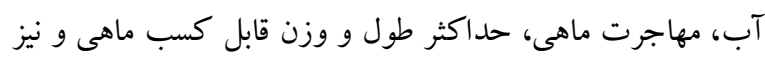
سلامت ماهى در اختيار قرار مىدهد (Esmaeili et al., 2001).

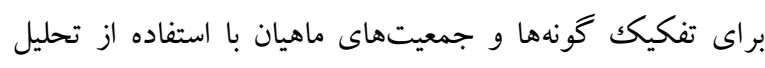

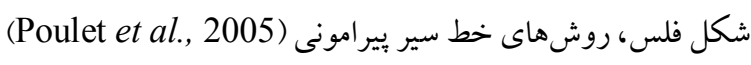

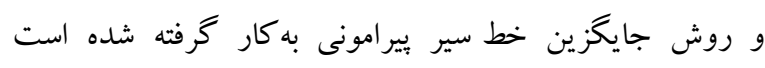
(Watkinson \& Gillis, 2005)

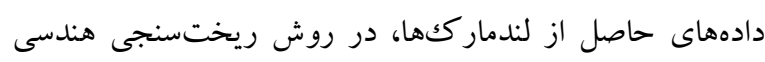

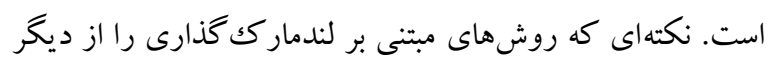


جدول 1- مشخصات ايستخاههاى تحت بررسى.

Table 1. The details of the studied stations.

\begin{tabular}{|c|c|c|c|c|c|c|c|c|}
\hline \multicolumn{2}{|c|}{ طول جغرافيايى } & \multicolumn{2}{|c|}{ عرض جنرافيايى } & \multirow{2}{*}{ - ارتفاع از سطح دريا (متر) } & \multirow{2}{*}{ تعداد نمونه } & \multirow{2}{*}{ رود } & \multirow{2}{*}{ سند امثان ايستاه } & \multirow{2}{*}{ كב } \\
\hline$r 1^{\circ}$ & $10^{\prime}$ & $\Delta \Delta^{\circ}$ & $1 V^{\prime}$ & & & & & \\
\hline & - & & - & - & r & كارون & بشار & r \\
\hline$r \cdot{ }^{\circ}$ & $r^{\prime}$ & $\Delta 0^{\circ}$ & $r v^{\prime}$ & Fi. & rr & زهره & خيرآباد & r \\
\hline$r r^{\circ}$ & $\mathrm{rA}^{\prime}$ & $4 \Lambda^{\circ}$ & $r F^{\prime}$ & $\Delta \Delta 1$ & $r$. & دز & مازو & r \\
\hline$r^{\circ}$ & $r q^{\prime}$ & $F V^{\circ}$ & $\Delta v^{\prime}$ & $\Delta \Delta q$ & ir & كشكان & كرداب & $\Delta$ \\
\hline$r \cdot{ }^{\circ}$ & f.' & $0.0^{\circ}$ & $1 N^{\prime}$ & rrr & ir & جراحى & به:بهان & 9 \\
\hline & - & & - & - & rq & - & بالنكان & v \\
\hline & - & & - & - & TV & - & سيروان & $\wedge$ \\
\hline & - & & - & - & rq & - & كوشك بهرام & 9 \\
\hline & - & & - & - & $\Delta 1$ & - & شور آباد & 1. \\
\hline
\end{tabular}

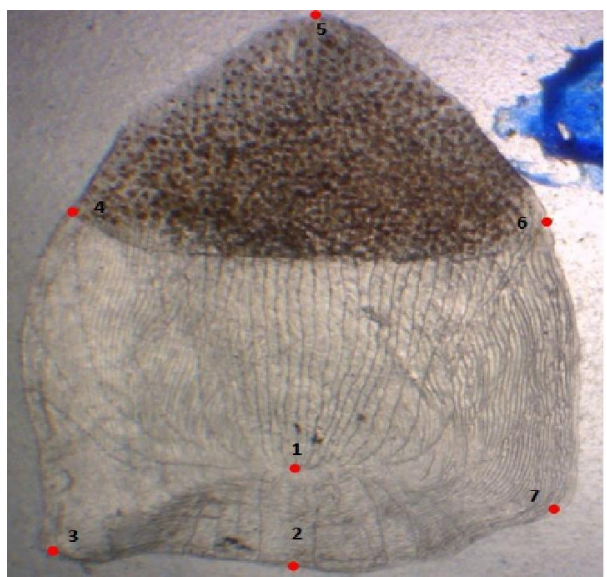

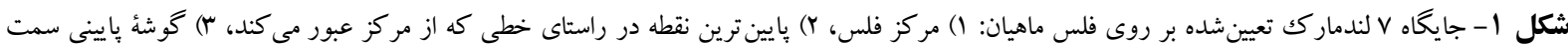

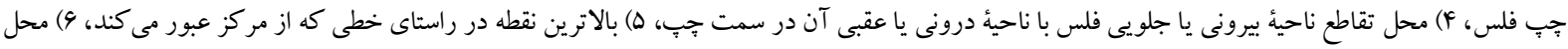

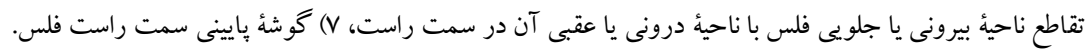

Fig. 1. Location of the 7 Landmarks on the scales: 1) The center of scale, 2) The lowest point along the line that passes through the scale center, 3) The lower left corner of scale, 4) The interface of the anterior and posterior parts on the left side of the scale, 5) The highest point along the line that passes through the center of the scale, 6) The interface of the anterior and posterior parts on the right side of the scale, 7) The lower right corner of the scale.

واريانس جندمتغيره (Manova) و تحليل خوشهاى با استفاده از

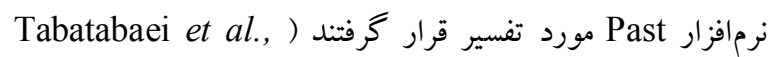
2014). تفاوت شكل فلس در جمعيتهاى تحتبررسى براساس شكل ميانگين (Consensus configuration) هر گروه از ماهيان در تحليل خوشهاى و انحراف از ميانخين شكل فلس جمعيتها از يكديخر با استفاده از شبكهُ تغييرشكل بهوسيله نرمافزارهاى (version1.20) و tpsSmall (past بررسى شد

(Rohlf, 2003)
هندسى بريائُ مختصات لندمار كهها است كه براى بررسى تغييرات

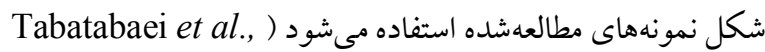
2014). بهمنظور حذف ويز گیىهاى غيرشكلى و استخراج دادههاى شكل، جايگاه لندمار ككهاى تمام نمونهها با استفاده از تحليل GPA (Generalized Procrustes Analysis) بروكراست روىهم گذارى شدند (Tabatabaei et al., 2014). سبس، دادههاى حاصل با استفاده از تحليل جندمتغيره تجزيه به مؤلفههاى اصلى (PCA))، تحليل همبستخى كانونيك (CVA)، تحليل 
اين مطالعه با هدف استفاده از شكل فلس بهمنزله روشى آسان و سريع در شناسايى ده نمونه از كونه Gufa به روش ريختسنجى هندسى انجام شد. نتايج نشان داد كه تفاوت معنىدارى ميان اشكال فلس بعضى جمعيتهاى تحت مطالعه وجود دارد، اما تفاوتهاى يادشده نمىتواند جمعيتهاى گونهُ تحت بررسى را بهطور كامل از هم جدا كند. مطالعات نشان داده است كه فلسها مى تو انند در بررسىهاى ردهبندى، شجرهشناسى، رشد، تاريخهُ زندگى، وقايع زندگى (دوران رشد سريع يا كند)، اكولوزى و Coilie \& Rousseau, ) محيط زيست مورد استفاده قرار بكيرند .(1974; Johal \& Dua, 1994; Johal \& Sawhney, 1997 استفاده از شاخصهاى ريختى و شمارشى كاربردهاى وسيعى در بررسى جمعيتهاى ماهيان، سيستماتيك و جداسازى كونهاى آنها از يكديگر (Ruban, 1998) و تشخيص دور گههاى طبيعى دارد (Kilambi \& Zdinake, 1981). نتايج يزوهش حاضر نشان داد تفاوت شكل فلس در بين بعضى از جمعيتهاى گونه Gufa در رودخانهاى مختلف معنىدار است، اما با توجه به تحليل مؤلفهاى اصلى (PCA) و تابع كانونيك (CVA) نمونهها ازنظر شكل فلس داراى هميوشانى هستند و نمىتوان جمعيتها را باتوجه به شكل فلس بهطور كامل از هم جدا كرد (اشكال Y و r). در مطالعه Tabatabaei و همكاران (2014) نيز مىتوان نتايج مشابهى در بين گونهاى يكك جنس مشاهده كرد. آنها در بررسىهاى خود نتايج مشابهى بهدست آوردند، اما توانستند در سطح جنس، ماهيان تحت بررسى را با استفاده از شكل فلس جدا كنند. در كذشته تصور مىشد تغييرات ريختى صرفاً زنتيكى است، اما امروزه مشخص شده كه منشأ اين Akbarzadeh et al. ) تغييرات هم محيطى و هم زنتيكى است 2009). يُزوهشهاى اخير مشخص كرده است كه اختلافات ريخت شناختى بين گروههاى مختلف ماهيان الز اماً آنها را از لحاظ زنتيكى جدا نمى كند و درعوض، در يارهاى از موارد تفاوتهاى ريختشناختى صرفاً ناشى از محيط است و اختلافات زنتيكى هيج نقشى در آن ندارد (Swain \& Foote, 1999). بدين ترتيب نقش محيط به عنوان عامل اصلى تغييرات ريختى به اثبات رسيده است (Tudela, 1999). برخى تفاوتها و شباهتهاى بين جمعيتى ممكن است با فاكتورهاى مختلف زيستگاه از قبيل دما،

\section{نتايج} در نتايج حاصل از تحليل PCA)، دو مؤلفهُ اصلى (PC) اول و

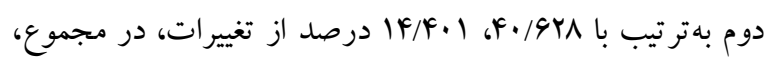
هو.rه درصد از تغييرات را شامل مىشدند (شكل r). تحليل

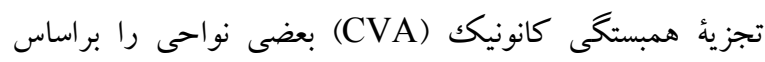

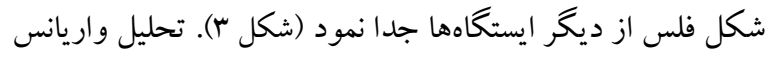

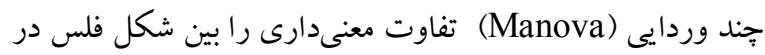

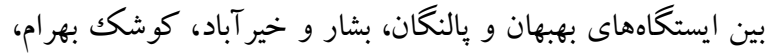

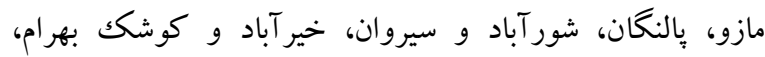

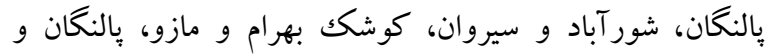

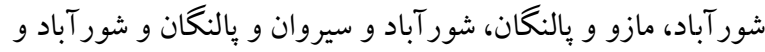

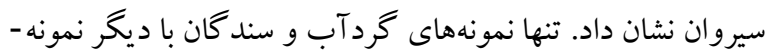
ها تفاوت معنىدار نداشتند. لندمارككهايى كه تغييرات زيادى داشتند و در بين ايستگاهها داراى تفاوت بيشترى بودند شامل لندمار كتهاى F، 9، V و r هستند. اين لندمار كها در كنارههاى

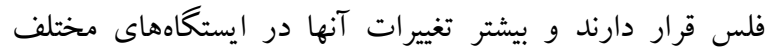

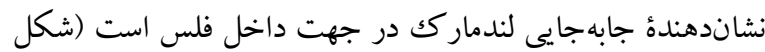
F). لندمار ككهاى qو F به سمت لندمارك هـ و داخل و لندمار كك-

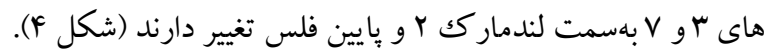
لندمار ككهاى ه، ا و Y كه بهترتيب در امتداد محور طولى فلس

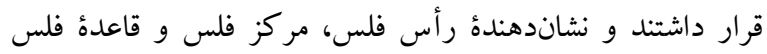
هستند، در طول محور طولى فلس جابهجا مىشوند. لندمارك هـ هرأه

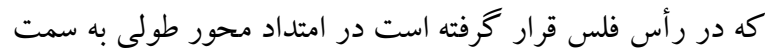

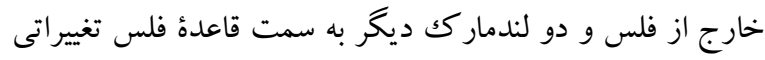

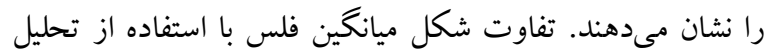
خوشهاى در شكل ه هنان داده شده است. همانطور كه در شكل مئل هـ نشان داده شده است، ايستخاههاى پالنگان، سند كان، شور آباد و

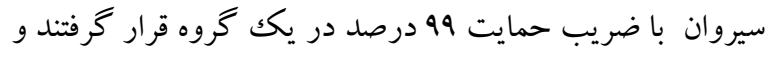

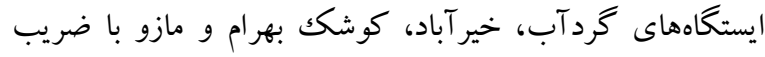

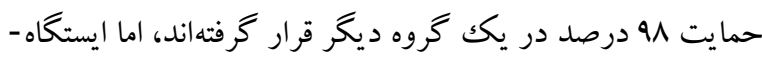

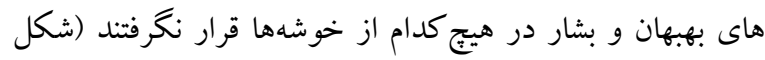




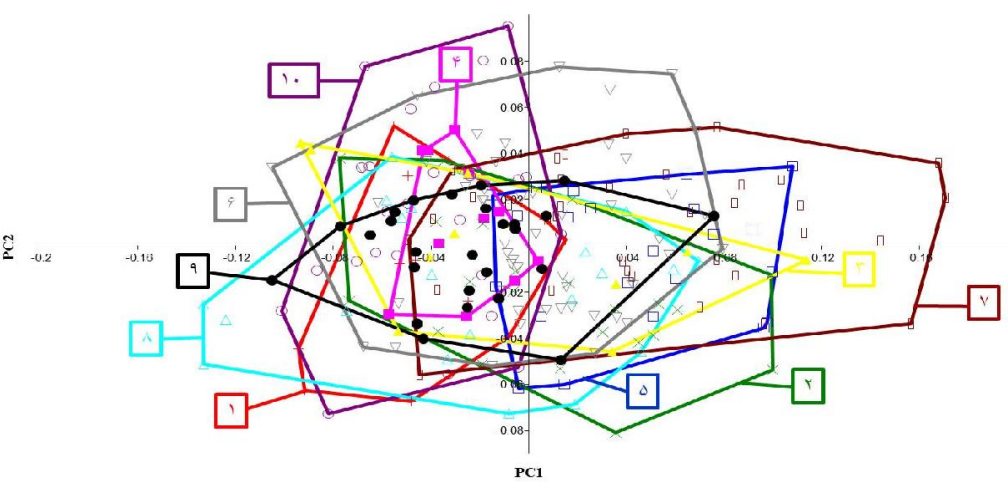

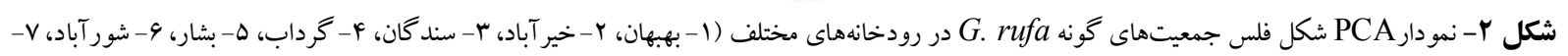

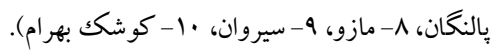

Fig. 2. PCA diagram of scale shapes in different G. rufa populations in different rivers (1. Behbahan, 2. Kheirabad, 3. Sendegan, 4. Gerdab, 5. Beshar, 6. Shorabad, 7. Palangan, 8. Mazo, 9. Sirvan, 10. Koshk bahram).

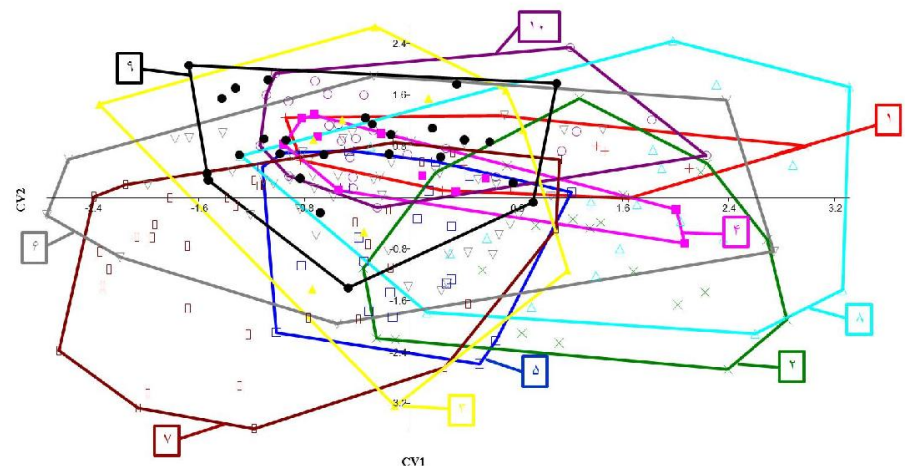

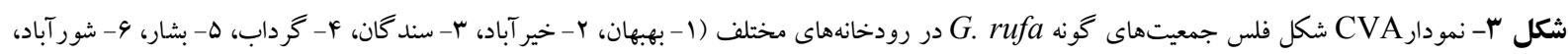

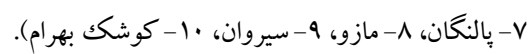

Fig. 3. CVA diagram of scale shapes of different G. rufa populations in different rivers including 1. Behbahan, 2. Kheirabad, 3. Sendegan, 4. Gerdab, 5. Beshar, 6. Shorabad, 7. Palangan, 8. Mazo, 9. Sirvan, and 10. Koshk Bahram Rivers.

يوشانى مشاهدهشده محتمل دانست، كه قضاوت نهايى در باب اين

فرضيات نيازمند انجام مطالعات بومشناختى و زُنتيكى در زمينهُ

ردهبندى و ويز گىهاى زنتيك جمعيت ماهيان تحت بررسى است.

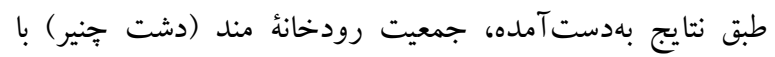

ديخر جمعيتها در YA صفت قابل اندازهيرى و 9 صفت قابل

شمارش اختلاف معنىدارى داشت. اخيراً ماهيان Garra در

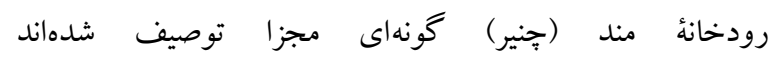
كه با تفاوتهاى گزارش شده (Sayyadzadeh et al., 2015) توسط Ghalenoei (2010) و همكاران مطابقت دارد.
كدورت آب، دسترسى به مواد غذايى، شدت جريان و عمق آب ارتباط داشته باشد (Mathews, 1988). در باب كونة تحت بررسى (G. rufa) در اين مطالعه نيز

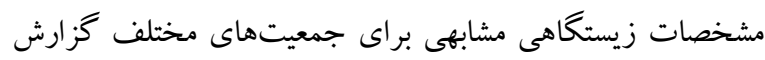
شده است. معمولاً كونه هاى جنس Garra با ديسك دهانى دهانى كامل

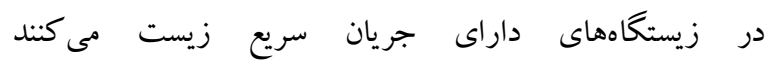
(Hashemzadeh Segherloo et al., 2017) مطالب يادشده در بارهُ تأثير محيط بر شكل بدن و فلس مىتوان احتمال تأثيرات محيطى را در تشابه نسبى شكل فلسها و هم- 


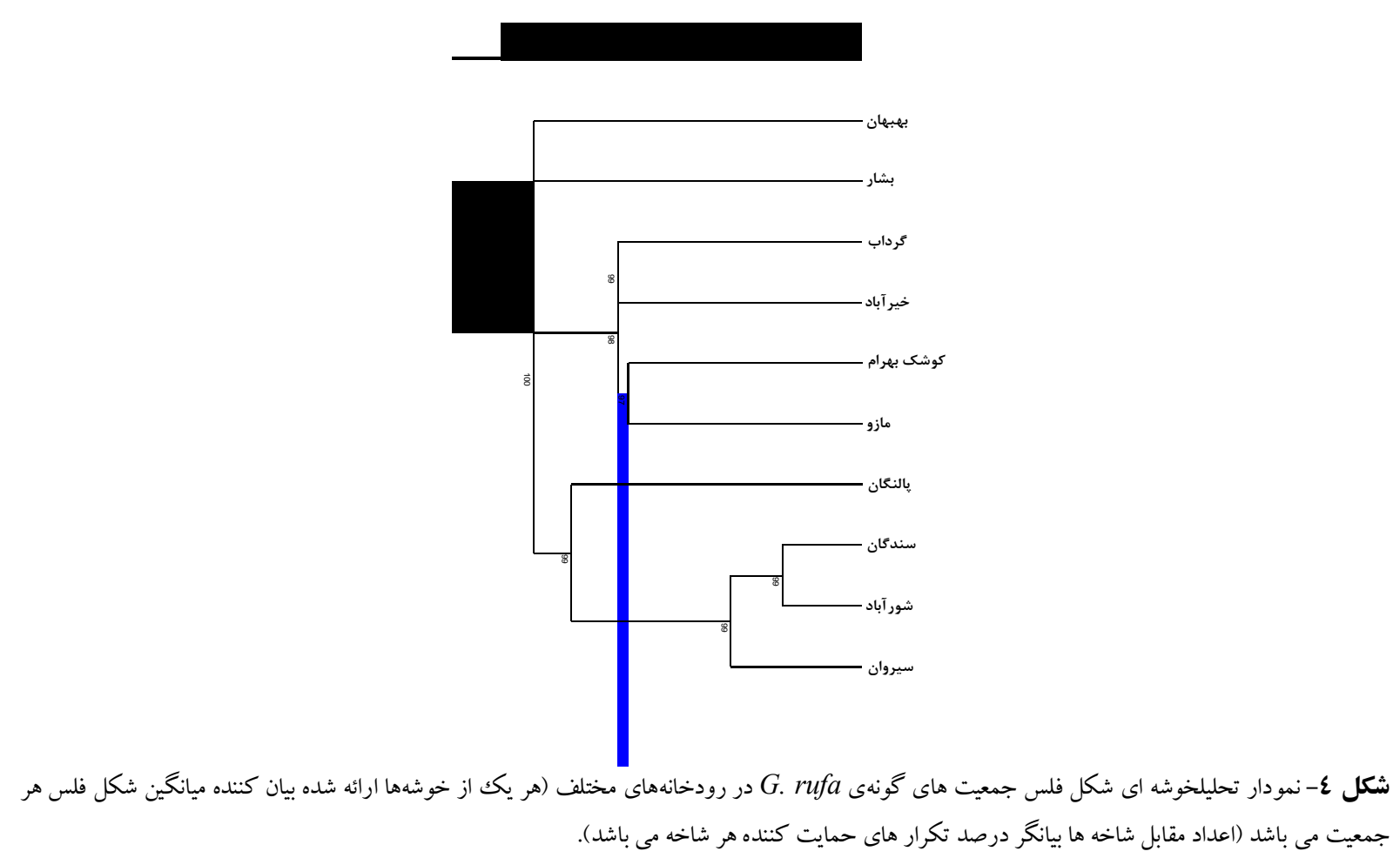

Fig. 4. Cluster analysis chart of scale shapes for different ppopulations of G. rufa in different rivers (the values represented on the branches referred to as "branch support values").

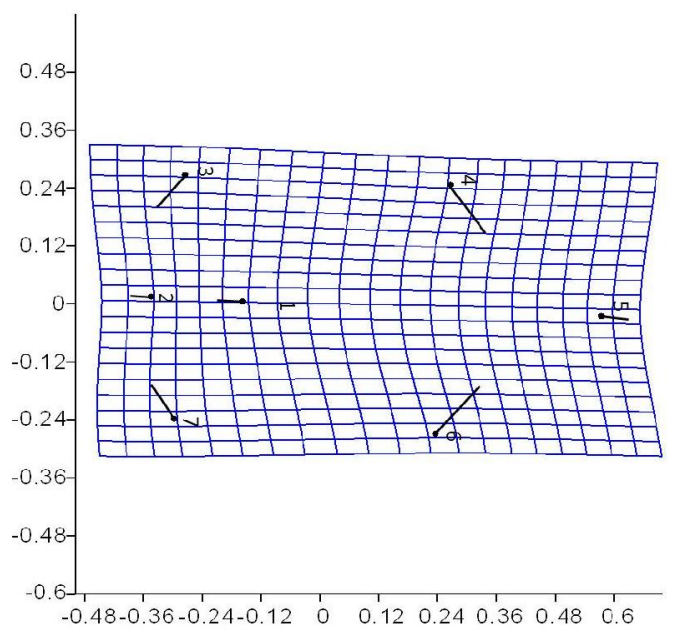

شكل 0- جهت يراكنش لندماركك هاى مربوط به جمعيتهاى كونه G. rufa در رودخانه هاى مختلف.

Fig. 5. The landmark orientation distribution in populations of $G$. rufa in different rivers.

مطالعه نمونههاى ماهيان رودخانه مند دردسترس نبوده و استفاده نشده است. آنها همجنين با استفاده از صفات يادشده در بين ديخر ماهر جمعيتها تفاوت قابل توجهى مشاهده نكردند. در اين مطالعه نيز
Ghalenoei

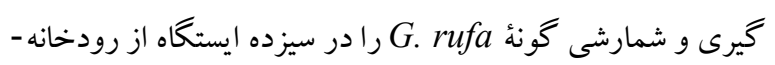
هاى حوضة آبريز دجله و خليجفارس بررسى كردهاند. در اين 
نتايج بررسى Tabatabaei و همكار ان (2014) نمى توان دست-

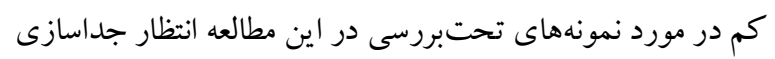

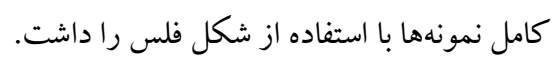

سباستزارى

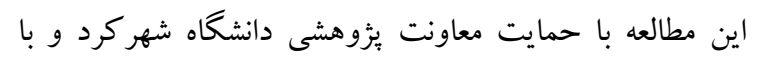

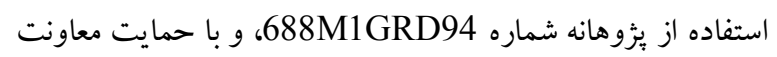
يزوهشى دانشكاه شهيد بهشتى انجام شده است كه نغارند كان بدينوسيله از حمايتهاى يادشده سِّاسگز ارى مى نمايند.

\section{REFERENCE}

Abdoli, A. 2000. The inland freshwater fishes of Iran. - Iranian Museum of Natural and Wildlife 378 pp, Tehran.

Akbarzadeh, A., Karami, M., Nezami, S.A., Mojazi, A.B., Khara, H. and Eagderi, S. 2009. A co-mparative study of morphometric and meristic characters of pikeperch $\mathrm{Sa}$ nder lucioperca (L.) in Iranian waters of Caspian Sea and Aras Dam Lake. - J. Fish. (Iranian J. Nat. Resources) 22: 535-545.

Coad, B.W. 1995. Freshwater Fishes of Iran. - Acta Scientiarum Naturalium Academiae Scientiarum Bohemicae 29: 1-64.

Coad, B.W. 2016. [Website] http://briancoad.com (acessed 3 March, 2016).

Coillie, V.R. and Rousseau, A. 1974. Composition minerate desecailles du Catostomus commersoni issued deux milieus differents: etude par microscopie electronique and analytique. - J. Fish. Res. Board. CAN. 31: 63-66.

Esmaeili, H.R., Ebrahimi, M., Ansari, T.H., Teimory, A., and Gholamhosseini, G. 2009. Karyotype analysis of Persian stone lapper, Garra persica Berg, 1913 (Actinopterygii: Cyprinidae) from Iran. - Curr. Sci. India. 96: 959-962.

Ghalenoei, M., Pazooki, J., Abdoli, A., Hassanzadeh Kiabi, B. and Golzarianpour, K. 2010. Morphometric and meristic study of Garra rufa populations in Tigris and Persian Gulf Basins. - Iran. Sci. J. Fisheries. 3: 107-118.

Grassberger, M., and Hoch, W. 2006. Ichthyotherapy as alternative treatment for patients with psoriasis: A pilot study. - Evid-Based Compl. Alt. 3: 483-488.

Hashemzadeh Segherloo, I., Abdoli, A., Eagderi, S., Esmaeili, H.R., Sayyadzadeh, G., Bernatchez, L., Hallerman, E., Geiger, M.F., Özulug, M., Laroche, J. and Freyhof, J. 2017. Dressing down: convergent reduction of the mental disc in Garra (Teleostei: Cyprinidae) in the Middle East. - Hydrobiologia. 785: 47-59.

Ibanez, A. L., Cowx, I.G. and O'Higgins, P. 2007. Geometric morphometric analysis of fish scales for identifying genera, species, and local populations within the Mugilidae. - Can. J. Fish. Aquat. Sci. 64: 1091-1100.

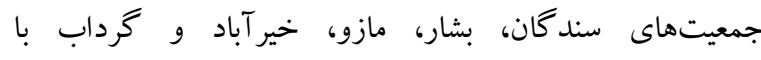
مطالعه Ghalenoei (2010) مشابه است و نتايج مشابهى با استفاده از شكل فلس مشاهده شده است. معمولاً ماهيانى كه در دوران اولئ زندگى دار اي محيط مشابهى هستند از لحاظ ريختى وضعيت

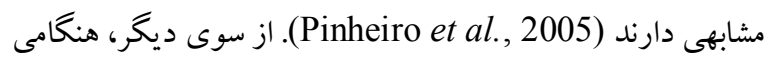
كه ماهى در محيط جديدى قرار گيرد، اين امكان وجود دارد كه

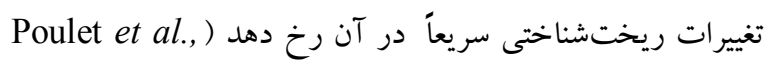
2004). Poulet و همكاران (2005) نيز شكل فلس سه جمعيت از Vونهُ Viaur رودخانه Leuciscus leuciscus burdigalensis فرانسه را با استفاده از روش خط سير بيرامونى بررسى كردند و به اين نتيجه رسيدند كه ميزان تفاوت شكل فلس ميان جمعيتهاى مختلف وابسته به فاصله است و نشاندهنده تفاوت فاكتورهاى محيطى نواحى بالادست و باييندست رودخانه است. همجنين، با لـا توجه به وجود انشعابات متعدد در رودخانه و تفاوت در جايگاه تخمريزى جمعيتهاى مختلف L.l.burdigalensis، امكان جدا بودن زنتيكى اين جمعيتها و در نتيجه احتمال تأثير محيط و زمينه زنتيكى متفاوت بر شكل فلس وجود دارد. در بررسى گروه بندى

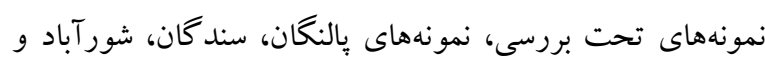

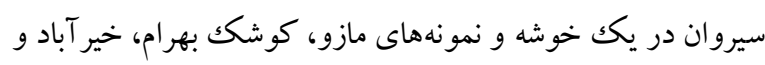
كردآب نيز در يكك خوشهُ مجزا قرار كرفتند. با توجه به اينكه در خوشهها نمونههايى با فاصلة جغر افيايى دور از هم و از حوضههاى

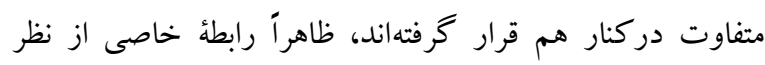
جغرافيايى در بين اشكال فلس وجود نداشته و بيشتر تفاوتها و تشابهها تحت تأثير عوامل ديخرى مثل محيط يا زنتيكك است كه ونه اين موارد بايد از نظر بومشناختى و زُنتيك جمعيت تحت بررسى بيشترى قرار كيرند تا بتوان قضاوت دقيق ترى ارائه داد.

درمجموع نتايج اين مطالعه نشان مىدهد كه در بين نمونههاى ماهى G. rufa در رودخانه Gاى تحت مطالعه تفاوت معنىدارى ازنظر شكل فلس وجود دارد، اما تفاوتها در حدى نيست كه بتوان از آنها براى جداكردن نمونها در سطح جمعيتهاى كونهُ يادشده استفاده كرد. علىرغم آنكه شناسايى گونهها براساس إس شكل فلس روشى سريع و كمهزينه نسبت به روشهاى زنتيكى است و امكان بررسى افراد بيشتر و شناسايى تنوع موجود را فراهم مى آورد (Ibanez et al., 2007)، اما برياية نتايج اين مطالعه و 
Jawad, L.A. and Al-Jufaili, S.M. 2007. Scale morphology of greater lizardfish Saurida tumbil (Bloch, 1795) (Pisces: Synodontidae). - J. Fish Biol. 70: 1185-1212.

Johal, M. S. and Dua, A. 1994. SEM study of the scales of freshwater snakehead, Chana nctatu (Bloch) upon exposure to endosulfan. - B. Environ. Contam. Tox. 52: 718721.

Johal, M.S. and Sawhney, A.K. 1997. Lepidontal alterations of the circuli on the scales of freshwater snakehead, Channa punctatus (Bloch) upon exposure to malathion. Curr. Sci. 72: 367-369.

Kilambi, R.V and Zdinak, A. 1981. Comparison of early developmental stages and adults of Grass Carp Ctenopharyngodon idella, and hybridcarp (female grass Carp $\times$ male bighea, (Aristichthys nobilis). - J. Fish Biol. 19: 457-465.

Mathews W.J. 1988. Morphology, habitat use, and life history. In Patterns in Freshwater Fish Ecology. Chapman \& Hall, 756 pp, New York.

Pinheiro, A., Teixeira, C.M., Rego, A.L., Marques, J.F. and Cabral, H.N. 2005. Genetic and morphological variation of Solea lascaris (Risso, 1810) along the Portugese coast. - Fish. Res. 73: 67-78.

Poulet, N., Berrebi, P., Crivelli, A.J., Lek, S. and Argillier, C. 2004. Genetic and morphometric variation in the pikeperch (Sander lucioperca) of a fragmented delta. Archive fur Hydrobiolgie. 159: 531-554.

Poulet, N., Reyjol, Y., Collier, H. and Lek, S. 2005. Does fish scale morphology allow the identification of populations at a local scale? A case study for rostrum dace Leuciscus leuciscus burdigalensis in River Viaur (SW France). - Aquat. Sci. 67: 122-127.

Rohlf, F.J. 2003. tpssmal, thin-plate spline, version 1.20. Department of Ecology and Evolution, State University of New York at Stony Brook.

Ruban, G.I. 1998. On the species structure of the Siberian sturgeon Acipenser baerii Brandt (Acipenseridae). - J. Ichthyol. 38: $345-365$.

Sattari, M. 2003. Ichthyology I, anatomy and Physiology. Guilan University, 680 pp.

Swain, D.P. and Foote, C.J. 1999. Stocks and chameleons: The use of phenotypic variation in stock identification. Fish. Res. 43: 113-128.

Tabatabei, S.N., Eagderi, S., Hashemzadeh Segherloo, I. and Abdoli, A. 2014. Geometric and morphometric analysis of fish scales to identity genera, species and po- pulations case study: the Cyprinid family. - Taxo. Biosystem. 8:1-17.

Tudela, S. 1999. Morphological variability in a Mediterranean, genetically homogeneous population of the European anchovy, Engraulisencrasicolus. - Fish. Res. 42: $229-243$.

Watkinson, D.A. and Gillis, D.M. 2005. Stock discrimination of Lake Winnipeg walleye based on Fourier and wavelet description of scale outline signals. - Fish. Res. 72: 193-203.

$* * * * *$

Mansouri Khajeh Langi, A., Hashemzadeh Segherloo, I., Tabatabaei, S.N. and Abdoli, A. 2017. Geometric analysis of the scale shape to discriminate different populations of Garra rufa Heckel, 1843. - Nova Biol. Rep. 3: 319-326.

$$
\begin{aligned}
& \text { منصورى خواجهلنغى، ع.، هاشمزاده سقرلو، ا.، طباطبايی، س.ن. و : و }
\end{aligned}
$$

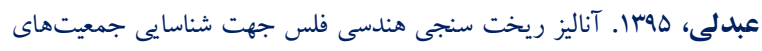

$$
\begin{aligned}
& \text { مختلف كونه Garra rufa Heckel, } 1843 \text {. - يافتهاى نوين در علوم }
\end{aligned}
$$

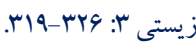

